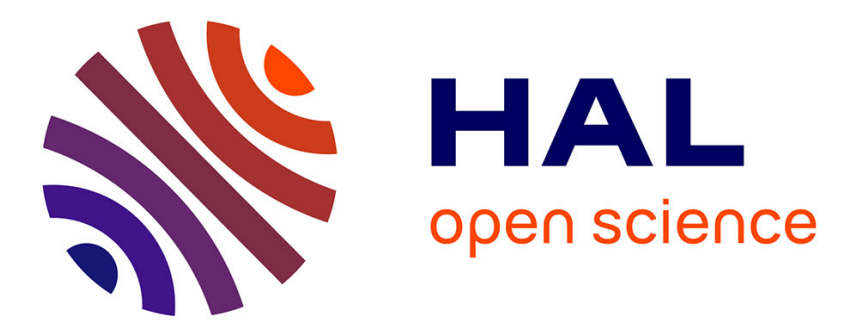

\title{
Antenna Radar Cross Section Measurement Within Mode-Stirred Reverberation Chamber
}

Ariston Reis, Francois Sarrazin, Philippe Besnier, Pouliguen Philippe, Elodie Richalot

\section{- To cite this version:}

Ariston Reis, Francois Sarrazin, Philippe Besnier, Pouliguen Philippe, Elodie Richalot. Antenna Radar Cross Section Measurement Within Mode-Stirred Reverberation Chamber. 2021 15th European Conference on Antennas and Propagation (EuCAP), Mar 2021, Dusseldorf, Germany. hal-03275711

\author{
HAL Id: hal-03275711 \\ https://hal.science/hal-03275711
}

Submitted on 1 Jul 2021

HAL is a multi-disciplinary open access archive for the deposit and dissemination of scientific research documents, whether they are published or not. The documents may come from teaching and research institutions in France or abroad, or from public or private research centers.
L'archive ouverte pluridisciplinaire HAL, est destinée au dépôt et à la diffusion de documents scientifiques de niveau recherche, publiés ou non, émanant des établissements d'enseignement et de recherche français ou étrangers, des laboratoires publics ou privés. 


\title{
Antenna Radar Cross Section Measurement Within Mode-Stirred Reverberation Chamber
}

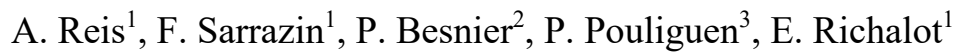 \\ ${ }^{1}$ ESYCOM Laboratory (UMR 9007), Univ Gustave Eiffel, CNRS, Francois, francois.sarrazin@univ-eiffel.fr \\ 2 INSA Rennes, CNRS, IETR-UMR 6164, F-35000 Rennes, France \\ ${ }^{3}$ Agence Innovation Défense, Direction Générale de 1'Armement, 75509 Paris, France
}

\begin{abstract}
This communication deals with radar cross section (RCS) measurement of a horn antenna within a reverberation chamber $(\mathrm{RC})$. RCs recently became a viable alternative to anechoic chamber to perform RCS measurement. Indeed, one can benefit from the RC statistical properties to retrieve the line of sight wave among the multiple reflections that occur within the cavity. It is the first time that this RC setup is used to measure the RCS of an antenna. More specifically, it is shown that it is possible to distinguish the antenna RCS measured for two different load conditions (short and match). As a consequence, it enables retrieving the antenna gain from RCS measurement performed in RC.
\end{abstract}

Index Terms-antenna, radar cross section, reverberation chamber.

\section{INTRODUCTION}

Radar cross section (RCS) allows quantifying how a target reflects an impinging wave toward the incoming direction (monostatic RCS) or other ones (multistatic RCS). This parameter is highly interesting for military applications including stealth where the RCS needs to be minimized so that a target becomes weekly observable for the radar enemy, and for civil applications such as RFID where the RCS of the tag needs to be maximized in order to be detected at a long range.

RCS measurement also found interest in the antenna domain in order to characterize antennas using its backscattering coefficient. Such technique avoids connecting the antenna under test (AUT) to a VNA. This is of particular interest for electrically small antennas for which the feeding cable disturbs both impedance and radiation characteristics of the AUT, and thus leads to inaccurate measurement. The RCS of an antenna can be divided into two parts: the structural mode and the antenna mode. The structural mode is related to the antenna as an object independently of its radiation properties whereas the antenna mode is related to the energy that is captured by the antenna at its port and reflected back depending on its load conditions. In order to retrieve antenna characteristics, one needs to distinguish these two modes among the backscattered field. This can be done by measuring the AUT RCS for several load conditions [1], [2].

The RCS is usually measured within an anechoic chamber (AC) so that the multipath components are mitigated thanks to the foam absorbers. However, recent works show its possible measurement within the diffuse field of a reverberation chamber (RC). A possible method consists in performing time

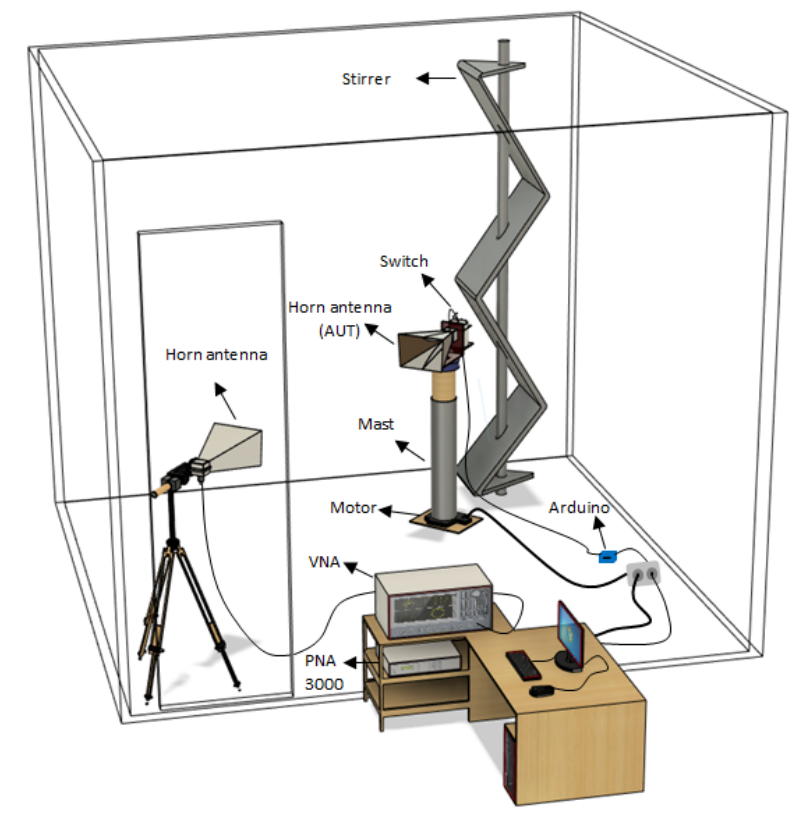

Fig. 1 Schematic of the antenna RCS measurement setup within reverberation chamber.

gating through Fourier transform in order to select only the time window that includes the line of sight contribution [3]. An alternative method takes benefit from the original field statistical properties within the RC to extract the RCS from the diffuse field environment without performing Fourier transform [4], [5]. The latter is used in this communication.

The objective of this communication is to show that small RCS variations due to the AUT load condition can be detected using measurement performed in RC. This would pave the way to antenna gain and radiation pattern measurement within $\mathrm{RC}$ as a reliable alternative to classical AC measurement.

\section{Measurement}

\section{A. Measurement Setup}

The measurement setup is presented in Fig. 1. The horn antenna on the left is connected to the VNA so that its reflection coefficient can be measured between 6 and $7 \mathrm{GHz}$ with 20001 frequency samples. This antenna is oriented toward another horn antenna that is the AUT in this study. The 
AUT is located on a motorized rotating mast that can rotate within the azimuthal plane (rotation from $-40^{\circ}$ to $+40^{\circ}$ with a $2^{\circ}$ step, $0^{\circ}$ being the antenna boresight direction). The AUT port is connected to a mechanical switch through a $30 \mathrm{~cm}$-long $50 \mathrm{ohms}$ cable. The switch allows connecting the AUT either to a short circuit or a $50 \mathrm{ohms}$ load. A mechanical mode stirrer is also located within the $\mathrm{RC}$ and the measurement are performed for 50 stirrer positions equally spaced over a full rotation.

\section{B. Measurement Method}

A first measurement is performed without the AUT, i.e., the AUT is removed from the RC. The measured reflection coefficient $S\left(f_{0}\right)$ of the antenna within an $\mathrm{RC}$ can be split into two parts as:

$$
S\left(f_{0}\right)=S_{F S}\left(f_{0}\right)+\left(1-\left|S_{F S}\left(f_{0}\right)\right|^{2}\right) H\left(f_{0}\right) \eta_{\text {ant }}
$$

where $S_{F S}\left(f_{0}\right)$ is the antenna free space reflection coefficient, that could be measured in an $\mathrm{AC}, H\left(f_{0}\right)$ is the RC transfer function and $\eta_{\text {ant }}$ is the antenna radiation efficiency. This second part is due to the reflections that occur within the cavity. Then, a second measurement is performed with the AUT located on the rotating mast so that (1) is now modified as follows:

$$
\begin{gathered}
S_{A U T}\left(f_{0}, \theta_{A U T}\right)=S_{F S}\left(f_{0}\right)+C\left(f_{0}\right) \sqrt{\sigma_{A U T}\left(f_{0}, \theta_{A U T}\right)} \\
+\left(1-\left|S_{F S}\left(f_{0}\right)\right|^{2}\right) H_{A U T}\left(f_{0}\right) \eta_{\text {ant }}
\end{gathered}
$$

where $S_{A U T}\left(f_{0}, \theta_{A U T}\right)$ is the measured reflection coefficient with the AUT oriented according to $\theta_{A U T}, H_{A U T}$ is the modified transfer function of the $\mathrm{RC}$ due the presence of the AUT and $C\left(f_{0}\right) \sqrt{\sigma_{A U T}\left(f_{0}, \theta_{A U T}\right)}$ is the line-of-sight backscattering contribution of the AUT toward the antenna. $C\left(f_{0}\right)$ is a coefficient that can be determined from the radar equation and $\sigma_{A U T}\left(f_{0}, \theta_{A U T}\right)$ is the RCS of the AUT. By subtracting the two measurements (performed for the same stirrer position [6]), it is possible to extract the RCS of the AUT through a regression process. More details about the method itself can be found in [5].

\section{Results}

The AUT RCS measured for two load conditions (short and match) is presented in Fig. 2 as a function of the azimuthal angle. It has to be noticed that the measurements of $S_{A U T}\left(f_{0}, \theta_{A U T}\right)$ for the short and match conditions are performed in a row (using the mechanical switch) with no change of the rest of the setup between these two measurements. We can see that the two measured RCS follow a similar pattern. However, the RCS related to the short-circuit load exhibits higher value than the one related to the matched load. Indeed, the backscattered field due to the antenna mode is maximum for a short-circuit whereas it almost vanishes when considering a matched load. Thus, such results could be

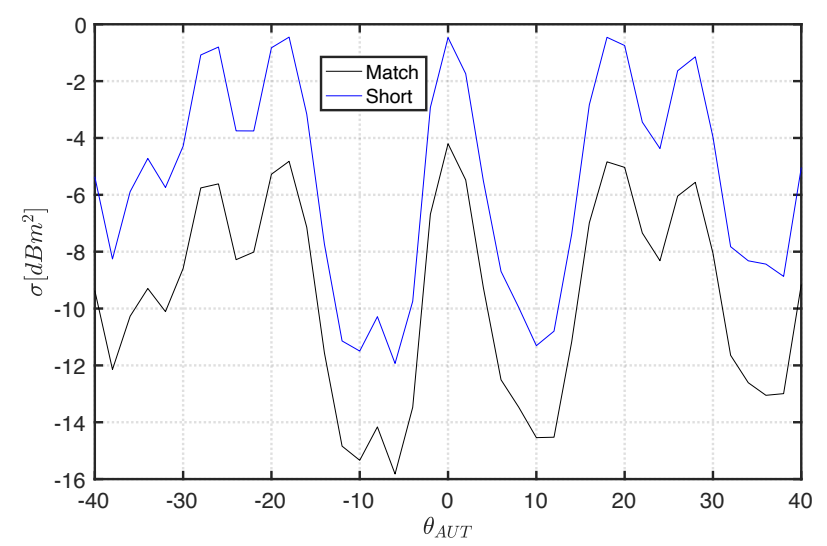

Fig. 2 RCS of the AUT as a function of the azimuthal angle for two AUT load conditions (short and match)

used to retrieve the antenna gain and radiation pattern by the use of some post-processing.

\section{CONCLUSION}

This is the first time that antenna RCS measurement are performed within an RC. We showed that the RCS variation due to the modification of the AUT load condition can be detected using such RC-based measurement setup. In future work, we intent to retrieve the antenna gain and radiation pattern from these two measurements to highlight the possible use of $\mathrm{RC}$ to perform contactless antenna characterization.

\section{ACKNOWLEDGMENT}

This work is financially supported by the Defense Innovation Agency within the French Ministry of the Armed Forces.

\section{REFERENCES}

[1] J. Appel-Hansen, "Accurate determination of gain and radiation patterns by radar cross-section measurements," in IEEE Trans. Antennas Propag, vol. 27, no. 5, pp. 640-646, September 1979, doi: 10.1109/TAP.1979.1142156.

[2] W. Wiesbeck and E. Heidrich, "Wide-band multiport antenna characterization by polarimetric RCS measurements," in IEEE Trans. Antennas Propag., vol. 46, no. 3, pp. 341-350, March 1998, doi: 10.1109/8.662653.

[3] A. Soltane, G. Andrieu, E. Perrin, C. Decroze and A. Reineix, "Antenna Radiation Pattern Measurement in a Reverberating Enclosure Using the Time-Gating Technique," in IEEE Antennas Wireless Propag. Lett., vol. 19, no. 1, pp. 183-187, Jan. 2020, doi: 10.1109/LAWP.2019.2957428.

[4] P. Besnier, J. Sol and S. Méric, "Estimating radar cross-section of canonical targets in reverberation chamber," in Int. Symp. Electromagn. Compat. - EMC EUROPE, Angers, France, 2017, pp. 15, doi: 10.1109/EMCEurope.2017.8094795.

[5] A. Reis, F. Sarrazin, E. Richalot, S. Méric, J. Sol, P. Pouliguen et P. Besnier, "Radar cross-section pattern measurements in a mode-stirred reverberation chamber: theory and experiments," unpublished.

[6] A. Reis, F. Sarrazin, P. Pouliguen, J. Sol, P. Besnier et E. Richalot, "Radar cross section measurement within reverberation chamber: stirrer position issues," Europ. Conf. Antennas Propag. (EuCAP), Copenhagen, Danemark, 2020, pp. 1-4. doi: 10.23919/EuCAP48036.2020.9135531 